Etnográfica

Revista do Centro em Rede de Investigação em

Antropologia

vol. $23(3) \mid 2019$

Vol. 23 (3)

\title{
Sob diferentes tetos: etnografando casas e revelando dimensões educativas e patrimoniais
}

Under different ceilings: ethnography of houses revealing educational and patrimonial dimensions

\section{Adriana Russi e Ceres Karam Brum}

\section{(2) OpenEdition}

\section{Journals}

Edição electrónica

URL: https://journals.openedition.org/etnografica/7484

DOI: 10.4000/etnografica.7484

ISSN: 2182-2891

\section{Editora}

Centro em Rede de Investigação em Antropologia

\section{Edição impressa}

Data de publição: 1 outubro 2019

Paginação: 693-715

ISSN: 0873-6561

\section{Refêrencia eletrónica}

Adriana Russi e Ceres Karam Brum, «Sob diferentes tetos: etnografando casas e revelando dimensões educativas e patrimoniais», Etnográfica [Online], vol. 23 (3) | 2019, posto online no dia 28 novembro 2019, consultado o 20 janeiro 2022. URL: http://journals.openedition.org/etnografica/7484 ; DOI: https://doi.org/10.4000/etnografica.7484

\section{(c) (†) (5)}

Etnográfica is licensed under a Creative Commons Attribution-NonCommercial 4.0 International License. 


\section{Sob diferentes tetos:} etnografando casas e revelando dimensões educativas e patrimoniais

\section{Adriana Russi e Ceres Karam Brum}

O artigo apresenta o diálogo entre duas etnografias, nas quais a casa é abordada como espaço de produção simbólica. Construído a partir de percursos etnográficos distintos, seu ponto seminal é a multiplicidade de sentidos do habitar para diferentes povos. As casas analisadas se revelaram lugares privilegiados de edificações cujos espaços territorializados apresentam dimensões educativas e patrimoniais plurais dos grupos investigados. Nessa aproximação, a casa/museu Maison du Brésil (residência de pesquisadores brasileiros na França) e a casa tamiriki dos ameríndios katxuyana (às margens do rio Cachorro, Oriximiná, PA) evidenciaram um reforço identitário, tanto para os brasileiros temporariamente morando em Paris, quanto para os katxuyana que regressaram ao seu território. Essas casas também desvelaram reflexões no campo da memória social, ao acionarem lembranças daqueles que as habitam.

PALAVRAS-CHAVE: casa, etnografia, educação, arquitetura, patrimônio cultural, memória social.

Under different ceilings: ethnography of houses revealing educational and patrimonial dimensions - The article presents the dialogue between two ethnographies, in which the house is approached as a space of symbolic production. Constructed from distinct ethnographic journeys, its seminal point is the multiplicity of meanings of dwelling for different peoples. The analyzed houses proved to be privileged places of buildings whose territorialized spaces present educational and heritage dimensions of the groups investigated. In this approach, the house/ museum Maison du Brésil (residence of brazilian researchers in France) and the house tamiriki of the Katxuyana amerindians (on the banks of the river Cachorro, Oriximiná, PA) evidenced the reinforcement of identity for both brazilians temporarily living in Paris, and the Katxuyana who returned to their territory. These houses also revealed reflections in the field of social memory by triggering recollections for those who inhabit them.

KEYWORDS: house, ethnography, education, architecture, cultural heritage, social memory.

RUSSI, Adriana (adri.russitm@gmail.com) - Departamento de Artes e Estudos Culturais, Universidade Federal Fluminense (UFF), Brasil.

BRUM, Ceres Karam (cereskb@terra.com.br) - Departamento de Ciências Sociais, Universidade Federal de Santa Maria, Brasil. 


\section{A CASA NA ANTROPOLOGIA E A MULTIPLICIDADE DE SENTIDOS DO HABITAR: TRAJETÓRIAS QUE SE CRUZAM}

Este artigo relata o encontro de dois percursos etnográficos que investigaram a casa em contextos socioculturais e simbólicos distintos. Um deles teve como objeto de pesquisa a Maison du Brésil (Brum 2014) e o outro a reconstrução da tamiriki entre ameríndios karib, os katxuyana (Russi 2014). De modo especial, destacamos as dimensões educativas e os diferentes sentidos do habitar desvelados nestas pesquisas.

Conforme Bromberger (2012), a temática da habitação é central em análises etnológicas. O tema tem sido apresentado a partir de várias perspectivas, como: a arquitetura e as tipologias habitacionais, a estética sob diferentes enfoques, o espaço vivido cotidianamente pelas pessoas, o binômio mobilidade/ sedentarização, entre outras.

O substantivo "casa" é um termo genérico e se refere a qualquer tipo de construção destinada à habitação ou à moradia temporária. De forma complementar, o termo "habitação", que remete ao verbo habitar, também significa casa, lugar de residência. Em muitas sociedades, tais termos são usados como sinônimos e remetem a um território. Por um lado, referem-se ao espaço onde se vive; por outro, aludem a aspectos identitários marcados nos comportamentos e nos corpos de seus habitantes.

As casas investigadas ilustram tipos de construções executadas pelo homem e se constituem em espaços de moradia (permanente ou temporária) de indivíduos ou grupos. Tanto no caso da Maison du Brésil, nos vários exemplos de indivíduos que ali habitam temporariamente, quanto no caso da tamiriki, vivenciada pelo grupo katxuyana em momentos de celebração e festas, essas casas se constituem igualmente em espaços de sociabilidade e de identificação.

Se os dicionários atribuem à casa a função de abrigar e proteger o homem das intempéries e ataques de terceiros (humanos ou animais), sua materialização em diferentes tamanhos e formatos revela a inventividade humana. O diálogo entre as duas etnografias revela a confluência entre as noções de abrigo e de território em seu aspecto simbólico. Revela, igualmente, dimensões educativas e patrimoniais que ensinam a viver o passado no presente, através da reconstrução do espaço tradicional da tamiriki, ou do aprendizado da nação, no caso da casa/museu Maison du Brésil.

A casa ou habitação, mais que um simples abrigo, é ela mesma uma construção cultural de uma sociedade que materializa a complexa interação entre normas, condições climáticas e potencialidades construtivas dos materiais (Philip L. Wagner, cit. em Rapoport 1972: ix). Assim, as formas construtivas se relacionam a um sistema técnico que, por sua vez, denota as relações entre os grupos humanos e seus ambientes. Aos fatores de ordem prática (matéria-prima disponível, solo, clima, etc.) seriam somados desejos de distinção social ou simbólica. 
Para Bromberger (2012), um estudo etnológico da casa reflete o complexo jogo de critérios, condições e limites que se interpõem tanto na construção quanto na ocupação da casa. Uma possibilidade de análise aborda o espaço doméstico como forma de expressão do ethos (Bromberger 2012), segundo a qual importa compreender em torno de quais categorias próprias uma sociedade se organiza: público/privado, dentro/fora, fechado/aberto, entre outras.

A importância do viés sociocultural nas análises sobre habitação é também ressaltada por Rapoport (1972). Exemplificando tal abordagem, destacamos Mauss (2003), com a proposição sobre a "morfologia social”, e Rivière (1996), com o estudo das casas na região da Guiana. ${ }^{1}$

Dessa forma, se pensarmos no conjunto de estudos na antropologia que remetem à casa, não estamos diante de tema inexplorado. Ainda sobre esse campo de produção, na França, são bem conhecidos os trabalhos de Lévi-Strauss (1957), ao analisar a casa bororo; Griaule (1966), que estuda a casa dogon; Bourdieu (1980), ao interpretar a casa kabyle; Ruegg (2011), que estudou as habitações camponesas; na antropologia portuguesa, Rosales (2015) analisou, a partir da cultura material, as casas de imigrantes na Europa. Voltando nossa atenção à temática da habitação indígena, os trabalhos de Faria (1951), Novaes (1983), Portocarrero (2010), Costa e Malhano (1987) criticam abordagens que seguem apenas a perspectiva ergológica.

Esses estudos enfocam diferentes habitações/casas em distintos contextos socioculturais e, nesse sentido, revelam as particularidades do habitar. A partir deles, poderíamos reconhecer na casa algumas recorrências: lugar de repouso, produção ou consumo de alimentos, relações parentais, etc. Tais estudos, tal como os casos aqui analisados, indicam a multiplicidade dos sentidos do habitar. Nos relatos sobre a Maison du Brésil e a tamiriki, é possível observar como esses espaços reiteram aspectos identitários, suscitam memórias - do país de origem, no caso dos brasileiros, e dos ancestrais, no caso dos ameríndios katxuyana - e são, ao mesmo tempo, locus de aprendizagem e de sociabilidade.

As casas etnografadas são percebidas em suas particularidades culturais. Revelam experiências de sociabilidade, intimidade e educação dos grupos estudados. As pesquisas remetem a dois tipos construtivos distintos. A primeira delas é a Maison du Brésil (Brum 2014), que há mais de meio século recebe estudantes/pesquisadores em Paris e é vinculada à imagem da arquitetura modernista brasileira na França. A segunda analisa a reconstrução de uma casa comunal - a tamiriki - de um povo indígena karib no norte do Brasil, em Oriximiná, Pará (Russi 2014). Esses percursos se cruzaram em junho de 2014, na Universidade de Edimburgo, durante o encontro da Associação Britânica de Antropologia, quando percebemos a convergência de algumas questões 
investigadas. A confluência do tema da casa e dos processos de territorialização dos espaços percebidos pela atuação dos grupos estudados suscitou a possibilidade da comunicação desses percursos.

O diálogo entre esses dois estudos não se circunscreve apenas à casa, como espaço de abrigo, acolhimento e intimidade, mas sobretudo às dimensões educativas e patrimoniais reveladas pelas etnografias. Os estudos apontam, por exemplo, para o aprendizado das fronteiras territoriais entre espaço público e privado. Tais fronteiras são, muitas vezes, apreendidas pelas práticas dos indivíduos e/ou grupos que as habitam e/ou frequentam. A própria ideia de casa como representação do mundo privado dos indivíduos é tensionada em ambos os estudos.

Além de habitação temporária para pesquisadores em Paris, que lá se hospedam para efetuar seus estágios de doutorado e pós-doutorado, a Maison du Brésil também se configura como museu aberto à visitação, desde 2002. Essa casa é patrimônio arquitetônico modernista e tem como um de seus objetivos divulgar a língua e a cultura brasileira na Europa. Apresenta aspectos educativos decorrentes de seu caráter museológico, colocando em diálogo e conflito os espaços públicos (museu e espaços de sociabilidade) e privados da casa. Percebemos que viver na Maison du Brésil se relaciona ao aprendizado de ser emigrante brasileiro no exterior, envolvendo aspectos educacionais formais e informais, os quais remetem a processos identitários plurais que dialogam com imagens do Brasil no exterior.

A tamiriki, por sua vez, tem em sua própria construção um objeto de aprendizagem informal, transmitida ao longo de gerações. Como os katxuyana viveram décadas sem colocar em prática esse saber-fazer, as memórias dos velhos foram acionadas por ocasião do regresso de parte desse povo ao seu território. Reocupar seu território significou, para eles, retomar certas práticas abandonadas quando viveram em outras localidades, com outros ameríndios. Associada a essa dimensão educativa está a própria reafirmação identitária de ser katxuyana, ou seja, nas palavras dos katxuyana, é importante esse "resgate" da própria cultura. Trata-se, nessa perspectiva, da dimensão patrimonial da casa tamiriki, um saber-fazer e ensinar para manter a tradição, a fim de que não seja esquecida pelas futuras gerações.

Como corolário da multiplicidade do habitar, as investigações sobre a Maison du Brésil e a tamiriki katxuyana descrevem as distintas maneiras de ocupação desses espaços, revelando suas dimensões simbólicas. Essas casas remetem a particularidades materiais e imateriais que as tornaram alvo de políticas patrimoniais ou de processos de patrimonialização. Tais espaços construídos materializam instigantes questões sobre o habitar que conectam essas pesquisas: Em que contextos culturais elas se dão? Como sincronia e diacronia dialogam a partir da atuação de sujeitos que protagonizam suas vivências com relação a essas casas? Passemos, então, às etnografias. 


\section{MAISON DU BRÉSIL: UM TERRITÓRIO BRASILEIRO EM PARIS}

Quando cheguei ${ }^{2}$ a Paris, em outubro de 2003, o primeiro de tantos impactos de uma viagem inicial à Europa foi a visão colorida, na Cité Internationale Universitaire de Paris (CIUP), da Maison du Brésil. Eu havia percorrido os arrabaldes da cidade até chegar à "Maison”. Enfim, havia chegado a Paris, ou melhor, em um lugar brasileiro em Paris.

A minha breve narrativa de uma chegada atribulada de medos da vida fora do Brasil, da perda de malas e de desentendimentos linguísticos - "eu não entendo esse francês" - se mostrou recorrente nas falas de vários colegas que vi chegar em 2003 e 2004 do hall envidraçado daquela casa. Eram expressões de cansaço e bagagens enormes arrastadas. As pessoas chegavam com um conjunto de expectativas e temores expressos em narrativas plurais que rememoram como tudo começou em Paris, dos novos amigos tornados parentes, dos desatinos e desacertos com orientadores e problemas de inserção nas universidades e laboratórios.

Ao conviver nesse universo pleno de significações, um mundo à parte de brasileiros em Paris se descortinou. Os pesquisadores brasileiros que vivem na Maison du Brésil não são imigrantes nem turistas, mas de alguma forma interagem dentro desses dois universos. Estudar em Paris envolve anseios de uma formação internacional, da busca de intercâmbio de pesquisas com profissionais franceses ou de outros países, mas remete também à busca por diferentes interesses ao acionar outras identidades. Em janeiro de 2010, retornei a Paris para melhor entender esse universo de pesquisa.

A Maison du Brésil é uma das 40 residências que formam o conjunto arquitetônico da CIUP. Algumas dessas residências (aproximadamente 23) possuem um "caráter nacional" e se destinam a acolher estudantes e pesquisadores de pós-graduação durante um período temporário. A CIUP foi concebida na década de 1920, como um espaço internacional de integração das elites intelectuais em formação em solo francês. Naquele momento, atendia à dupla necessidade de melhoria das condições de hospedagem estudantil, situada no Quartier Latin, e do desenvolvimento de um espírito internacionalista em prol da manutenção da paz mundial, abalada pela Primeira Grande Guerra.

A Maison du Brésil foi inaugurada em 1959, durante o governo de Juscelino Kubitschek de Oliveira. O prédio de concepção modernista, assinado por Lucio Costa e Le Corbusier, foi construído em três anos, com recursos do Ministério da Educação do Brasil (figura 1). A casa possui cinco andares, abriga em torno de 125 residentes em quartos individuais ou para casais. Seus espaços coletivos

2 Considerando que os estudos das casas aqui analisadas partiram de experiências individuais das autoras, optamos por alterar a pessoa do discurso ("nós" para "eu") nos textos que descrevem essas experiências. 


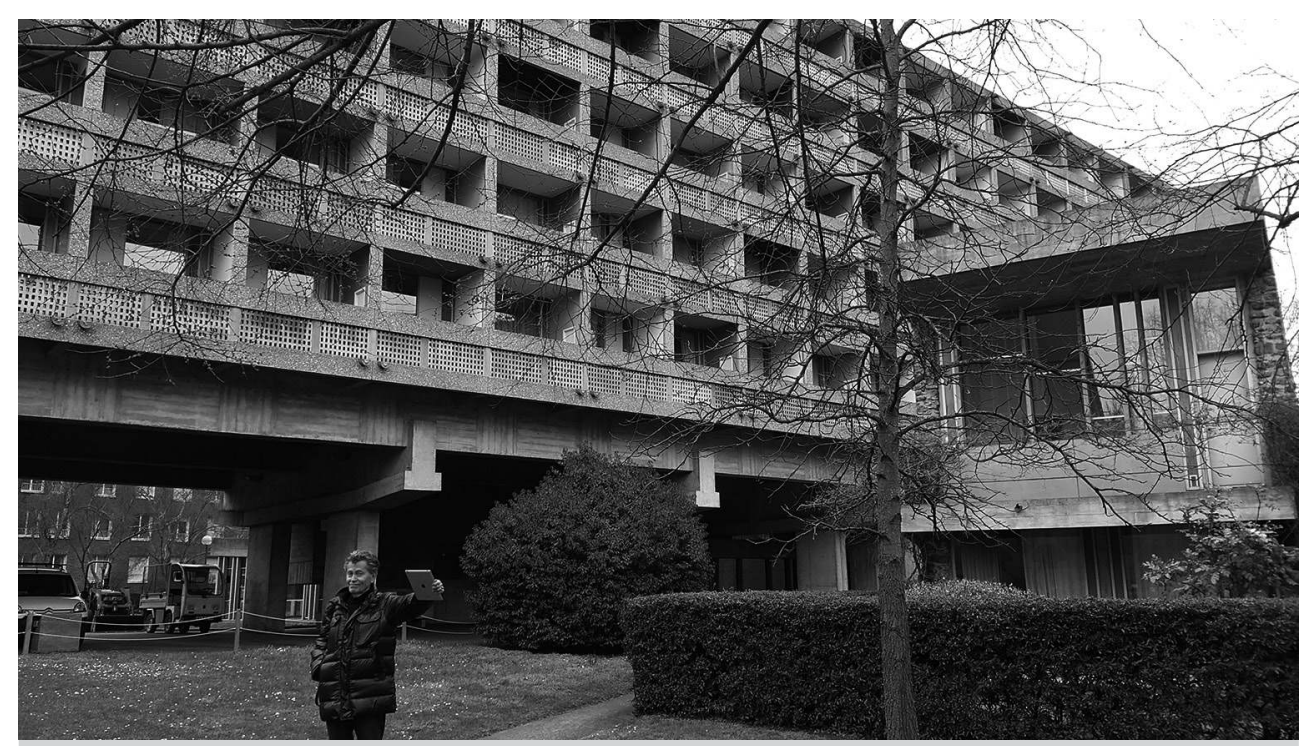

Figura 1 - Maison du Brésil. Fonte: acervo Ceres Karam Brum (Paris, junho de 2014).

incluem cafeteria, teatro, museu e salas de aula. Possui ainda uma estrutura de lavanderia e cozinhas em cada um dos andares da casa, bem como espaço administrativo, videoteca, biblioteca e o apartamento do/a diretor/a da casa. Ao longo de sua história, a casa teve diferentes administrações e estatutos jurídicos, que gravitaram em sua circunscrição do Ministério de Relações Exteriores ao Ministério da Educação. A Maison du Brésil foi alvo de manifestações estudantis em 1968 e viveu momentos críticos durante a ditadura militar, com o fim das subvenções do governo brasileiro, o que ocasionou sua degradação, agravada na década de 1990.

Em 1996, a arquiteta brasileira Inez Machado Salim assumiu a direção da "Maison" com a difícil missão de aproximar o governo brasileiro e conseguir recursos para sua restauração. Seu empenho resultou no fechamento da Maison du Brésil entre 1997 e 2000, para sua reconstrução, com a modificação no seu estatuto, propiciando a retomada de sua autonomia e reinauguração em 2002.

Sua história entre 2000 e 2012 se caracterizou por um modelo de administração voltado à sua reabilitação e viabilidade financeira, baseada no acolhimento prioritário de bolsistas do governo brasileiro, uma vez que a Coordenação de Aperfeiçoamento de Pessoal de Nível Superior (Capes) e o Conselho Nacional de Desenvolvimento Científico e Tecnológico (CNPq) financiaram boa parte de sua reconstrução. Também se caracterizou por seu planejamento e consolidação como espaço público de visitação (museu e quarto-testemunho, com visitas guiadas), o que, por seu turno, passou a acarretar certo impacto na vida dos moradores. 
Em julho de 2009, a Maison du Brésil comemorou seus 50 anos com uma grande festa e a produção de um vídeo. Em 2010, foi alvo de um trabalho de transformação em fundação de direito público, sendo reconhecida na França desde maio de 2010 como uma fundação de utilidade pública (FRUP). Várias casas nacionais da CIUP passaram a se inscrever nessa perspectiva, tendo por objetivo preservar a autonomia de casa nacional, conferindo-lhe "personalidade moral" (Salim 2013: 1) frente à administração da CIUP. A partir de modificações estatutárias acordadas entre as casas nacionais, essa transformação envolveu a Fondation Nacionale da CIUP e os governos interessados em mudanças, possibilitando a captação de recursos na França.

Analisar a situação, configuração e perspectivas da Maison du Brésil na atualidade não é uma tarefa fácil. Entre 2013 e 2017, a direção esteve a cargo de quatro diferentes pessoas, refletindo as dificuldades do cenário brasileiro no exterior. Uma análise de sua história e do próprio cotidiano de seus habitantes na atualidade demonstra a importância da residência para a história da educação nos dois países e para a formação de pesquisadores em diversas áreas. Durante os trabalhos de campo realizados entre 2004 e 2011 , observei que a Maison du Brésil é percebida por seus habitantes e frequentadores como um território brasileiro em Paris. Neste cenário desterritorializado (que remete à cultura brasileira em solo francês), são acionados elementos de identidades nacionais e regionais, através dos processos de circulação de pesquisadores entre os dois países.

A dimensão educacional do habitar a Maison du Brésil engloba múltiplos aprendizados situacionais, de acordo com as perspectivas de Lave (1996) e Ingold (2010). Eles abrangem a questão linguística e acadêmica, mas igualmente incidem sobre o desenvolvimento de novas posturas corporais e gostos relacionados ao habitar a casa. A adaptação ao clima e à comida francesa, a nova configuração espacial, que reduz o mundo privado da maior parte dos residentes a quartos de $16 \mathrm{~m}^{2}$ com inúmeras interdições decorativas, a reorganização do mundo coletivo, que implica em partilha de cozinhas, e o impacto produzido pela visitação do museu, com a presença de não residentes nos corredores da casa, são aspectos que podem ser significados como invasão de privacidade e suscitam reações dos residentes com relação aos visitantes, à direção, às normas da CIUP e da casa.

Observei que a Maison du Brésil se constitui pela atuação dos diversos sujeitos que a frequentam, em um território limítrofe de produção cultural, tanto no que concerne às identidades dos residentes que a habitam temporariamente, como de seus trabalhadores. Essas territorializações ocorrem de formas variadas quanto à disposição dos móveis nos quartos dos residentes, à organização das cozinhas, ao uso de imagens que remetem aos familiares e amigos deixados no Brasil, às referências à Maison du Brésil como "o favelão de Paris", "um bunker", ou "a Terra do Nunca", e à própria significação da 
situação espacial da casa na CIUP, por relação à história da colonização europeia. Um exemplo dessa territorialização do espaço aparece no próprio site da Maison du Brésil, vitrine da casa para futuros residentes e visitantes. ${ }^{3}$

Esse site descreve a "Maison" em relação à CIUP, qualificando-a como uma casa nacional, reforçando a ideia de território brasileiro em Paris, o que é evidenciado pela atuação e empenho do Estado em sua construção e cuidados de manutenção. Aspectos de sua história, estrutura habitacional, habitantes ilustres e inscrição no patrimônio histórico francês desde 1995, por sua relevância arquitetônica modernista, corroboram o argumento e a justificação da idealidade de um conjunto de características nacionais brasileiras a serem mostradas e cuidadas no exterior, com o objetivo de abrigar os pesquisadores que vão para a França receber uma formação cosmopolita. Nesse sentido, há uma pedagogização da nação brasileira no exterior através de um duplo aprendizado (para visitantes e residentes) que decorre desse processo de patrimonialização do espaço, mostrado e vivido como território brasileiro em Paris.

Essa definição da Maison du Brésil encontra respaldo no contexto espacial em que se insere. O site descreve a CIUP como um território internacional que abriga as casas nacionais e se constitui como espaço adequado para o convívio e interlocução das elites intelectuais internacionais em circulação na França.

Atualmente, os múltiplos aprendizados são percebidos na arquitetura das casas nacionais (o formato de pagode da Maison du Japon, as colunas romanas da Maison d'Italie, as cores e arquitetura modernista da Maison du Brésil), e nas diferentes formas de habitar esses espaços coletivos, considerando suas normas, e nas atividades culturais, que suscitam interlocuções com as nações e regiões que lá possuem suas casas, bem como com suas peculiaridades de organização e relativa autonomia, que se dinamiza ao longo da história da CIUP. Sua proposta contemporânea atualiza os ideais que lhe deram origem nos anos 1920 e objetiva favorecer o desenvolvimento da circulação internacional das elites em formação a partir de uma estrutura habitacional necessária, "integrada" à cidade de Paris, como proposta para o desenvolvimento individual de cada residente. Como projeto coletivo, a perspectiva de integração a partir do convívio de estudantes de diversas nações e regiões se expressa nas residências que a compõem e materializam a representação da diversidade-mundo, na proposta de espaços coletivos partilhados por todos os seus habitantes, como a Maison Internationale, por exemplo (figura 2).

A CIUP deseja evitar a formação de guetos nas diferentes residências através da brassage, ou seja, a ocupação de até 30\% de cada uma das residências por estudantes de nacionalidades diversas da nação que a "Maison" representa. A brassage objetiva a mistura a partir da efetiva circulação internacional entre os 


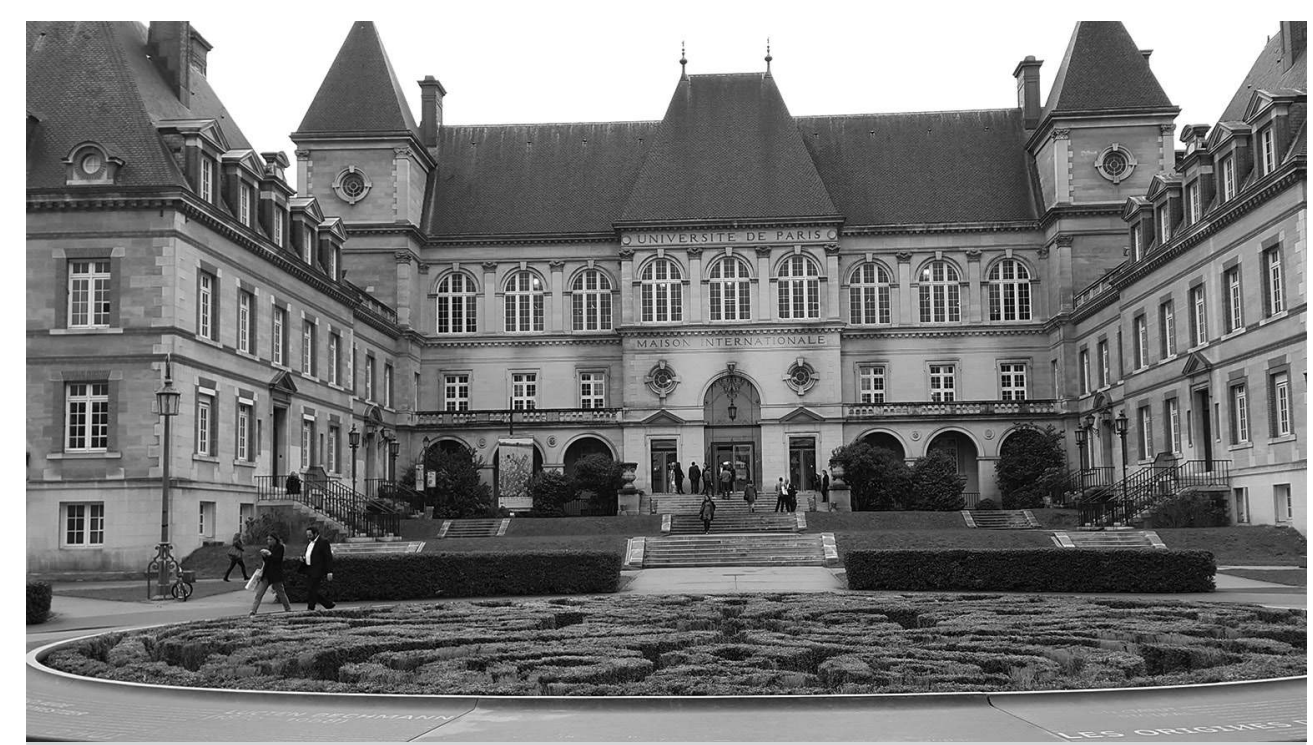

Figura 2 - Maison Internationale, CIUP. Fonte: acervo Ceres Karam Brum (Paris, abril de 2010).

residentes dentro dos limites da CIUP, colocando a questão da obrigatoriedade de interlocução com o mundo do outro como uma condição de sobrevivência.

Essa interlocução se percebe de forma peculiar na Maison du Brésil, onde o contato dos pesquisadores brasileiros que desejam residir na "Maison", as informações necessárias sobre a residência e a candidatura a uma vaga se dão através do site. Segundo Ruegg (2011:26), a representação e o imaginário que a casa inspira, ou os papéis a esta atribuídos, permitem reconstruir a sociologia, a história das ideias e a cosmologia das diversas concepções de habitar e do habitat. Tais questões extrapolam a dimensão deste texto, mas vale ressaltar que a casa se relaciona aos possíveis imaginários que ela incita. Dessa forma, as significações de afinidade entre pessoas que habitam um mesmo andar ou de convívio forçado remetem às territorializações desse espaço com o estabelecimento de laços sociais ou seu rechaço, pela criação de um parentesco simbólico que muitas vezes extrapola o tempo de convívio na casa, convertendo-se em aprendizado situacional de novas noções de família, decorrentes do habitar a Maison du Brésil.

O espaço modernista da Maison du Brésil passa a ser vivido como uma moldura, num cenário que se desenha ao sabor do fluxo de seus residentes em suas estadias:

"Primeiro, deixa eu ser sincera, [sentirei falta] da estrutura arquitetônica, porque eu sou feliz demais em morar nessa estrutura arquitetônica montada desse jeito genial, maravilhoso. Por essa estrutura de varanda, com quarto 
que dá visibilidade. Eu sinto falta dos cheiros, dos horários de luz, porque eu já sei tudo. Quando eu abro as janelas já sei o horário, pois já sei como funciona o sol. Disso tudo eu sentirei falta [...]" [Ana, doutorado em Psicologia, Rio de Janeiro, setembro de 2010].

Dessa forma, a vida da "Maison" é animada pelas chegadas e saídas dos seus habitantes temporários. Seu objetivo, do ponto de vista dos acordos celebrados entre a França e o Brasil, é fornecer suporte habitacional para um séjour educacional em Paris. A circulação de pesquisadores se circunscreve ao funcionamento da "Maison". Ela depende de um conjunto de pessoas (funcionários ou trabalhadores terceirizados) que desempenham diversas atividades na casa - administração, limpeza, recepção, reparos -, a fim de garantir os serviços de hospedagem acordados por ocasião da admissão de cada um dos residentes e os relativos ao funcionamento do museu, biblioteca, espetáculos, salvaguarda patrimonial e festas, que também ocorrem na casa e com os quais cada residente dialoga de forma peculiar.

É nesse sentido que a antropologia da casa se conecta à percepção do espaço da Maison du Brésil, em sua utilização simbólica que a destaca como um território brasileiro em Paris. Ortiz relaciona a constituição do território com a capacidade de manipulação simbólica do grupo em termos de delimitação espacial: "um grupo é um território capaz de delimitar suas próprias fronteiras" (Ortiz 2000: 62). Essa capacidade remete a um universo partilhado de códigos que permitem articular espaço e valores traduzidos em desejos demarcatórios, definidores das identidades do grupo, que forjam um território, permitindo recriações de seu universo de origem e, por sua vez, nos remetem à temática de desterritorialização/reterritorialização de identidades.

Durante o ano de 2010, tive a oportunidade de perceber que o habitar a casa adquire dimensões plurais na vida de seus residentes. A casa é, ao mesmo tempo, moradia, local de trabalho, lugar de sociabilidade e de recriação do Brasil em Paris, através de processos de desterritorialização de identidades. A casa é o próprio Brasil como nação que os acolhe na França. E o termo "Maison" passa a ser vivido e significado para além de sua tradução como "casa".

Carolina, doutoranda em dança em 2010, que habitava a Fondation Suisse, uma vez me confessou: "Maison para mim não é mais casa em francês. Maison, nem se discute, é Maison du Brésil, para sempre. É onde encontro o meu país, os meus amigos queridos". Carolina, de alguma forma, vive a casa como nação: a Maison du Brésil como o Brasil em Paris, em substituição e extensão territorial. A territorialização simbólica que ela efetua produz a ideia de uma fronteira delimitada no seu imaginário que encontra o Brasil em Paris através da "Maison". Essa é uma percepção que relaciona a educação como um processo de criação de cenários culturais, de produção de imaginários associados a processos educacionais (Brandão 2002). 
Ao estudar o sentido metafísico e existencial de cruzar as fronteiras nacionais em seus locais de entrada e saída, Löfgren se refere a uma pedagogia multifacetada do espaço que se expressa em relações de ansiedade e desconforto frente ao desconhecido: "Another common methaphor is the nation as a house and the immigrant as a visitor knocking at the door or the window, standind at the thresholdor in the backyard" (Löfgren 1999: 12). A metáfora da casa como nação se materializa e complexifica no cenário da CIUP, em que as maisons ora são significadas como território do acolhimento e integração, ora revelam as dificuldades de aproximação ao cenário francês.

Acerca da metáfora da nação como casa, Löfgren afirma: "there is an ethnification of national identity involved" (1999: 13). Essa significação da casa/ nação se expressa de diferentes formas ao dar visibilidade ao nacional em vivências rituais cotidianas, na produção de estereótipos regionais e nacionais, nas imagens do Brasil oferecidas na Maison du Brésil e na desconstrução de estereótipos por seus habitantes. Um exemplo disso se refere à imagem dos povos indígenas que ocupam o território brasileiro:

"Eu sou um dos amantes da Maison du Brésil, da Cité e do bandejão [refeitório para estudantes]. Mas eu acho triste estes estereótipos que são perpetuados. Tem uns índios (uma merda) na porta de entrada da casa e a gente acaba perpetuando isto. $\mathrm{Na}$ Casa da Argentina tem Borges e Cortázar" [Jacó, estudante de Matemática, Minas Gerais, 2010].

O depoimento revela o reconhecimento da dimensão de porto seguro e a boa estrutura que a Maison du Brésil oferece para se habitar na França. A crítica remete à presença constante de imagens estereotipadas do Brasil no universo simbólico de formação internacional dos pesquisadores. Um imaginário ambíguo, pois os brasileiros deixam o país desejosos de desfrutar do cosmopolitismo de uma formação internacional e a percebem como perpassada pelo local (Hannerz 1990). Esse localismo é aqui representado pela questão linguística e pela presença, na porta de entrada da Maison du Brésil, de dois "manequins" de índios em madeira de tamanho natural. Segundo a diretora da época:

"Aqueles índios estão ali, vou te contar porquê. Teve um ano que a Galerie Lafayette fez um evento ligado à cultura brasileira [...]. Então, a Galerie Lafayette estava cheia daquilo [...] e esses índios não são quaisquer índios colocados em qualquer lugar. Esses índios foram pintados pelos índios do Xingu, eles levaram para lá os manequins, e os índios do Xingu é que pintaram esse manequins [...] e a Galerie Lafayette trouxe tudo para cá [...]. Quando terminou o evento, eles [...] doaram para a embaixada. [...] Passados alguns meses, a embaixada me liga e pergunta se queria ganhar os índios: 'Claro que eu quero!' Eles vieram trazer os índios. Os cocares maravilhosos, 
aquelas coisas todas, tinham sumido! A única pena que sobrou foi aquela ali, daquele índio! Os índios chegaram todos quebrados [...] de dez só sobraram aqueles dois índios que eu podia ainda usar. Aí eu peguei os índios e coloquei na orelha do teatro. Ficaram lá muito tempo; depois um dia, alguém fez não sei o quê e teve que tirá-los, desceram os índios de lá. Eu peguei os índios e coloquei dentro da sala de informática, ficaram ali de guarda da sala da informática. Depois quando a gente fez a sala de... a videoteca, os índios não cabiam mais lá. Aí eu falei: 'Quer saber? Vou colocar eles vigiando a porta da casa'. Pra mim, aquilo é um objeto da nossa cultura, da nossa identidade nacional, pra mim é um objeto de arte [...] um manequim de loja, que é pintado pelos índios do Xingu [...]. Pra mim, é parte da nossa identidade nacional, eu queria colocar eles em um lugar de maior destaque, mas eu não quis mais subir com eles para não ficar quebrando, botei ali e gostei do lugar! Achei ótimo, eu deixei ali, é bom que ninguém está mexendo! E pra mim, todo mundo gosta! Ninguém nunca me falou que não gosta! [... Estão ali porque ninguém falou comigo sobre os do painel, que tem os portugueses ali todos vestidos de nobres, está ali a nobreza, os índios e os escravos do lado!" [entrevista com a diretora, Inez Machado Salim, 2010].

A presença desses índios provoca profundas inquietações. Essa imagem do Brasil oferecida a visitantes e residentes já na entrada da casa demarca um território povoado também por outros símbolos menos ostensivos, mas igualmente visíveis, que remetem ao Brasil, como os cartazes dos murais, cores, plantas e placas comemorativas. O contato com os índios em madeira e a perplexidade que provocam remete a uma interpretação negativa dessa materialidade por relacioná-la à incivilidade, à irracionalidade.

O rechaço aos índios, metaforicamente, remete ao Brasil como um país de bárbaros, de índios que necessitam ser civilizados e colonizados pelos franceses, no contexto da CIUP, em contraposição à imagem destacada da Argentina que apresenta, na entrada de sua casa, referências de seu universo erudito Cortázar e Borges. Talvez a revolta se relacione a uma percepção da posição colonizadora que a imagem dos índios enseja, pois remete a interpretações repletas de preconceitos e subjetividades de um Brasil como o país das cores, do futebol, do carnaval, da nudez e da preguiça, e não da produção intelectual. Ela nos remete igualmente a uma dificuldade de "deglutição" do colonialismo, já expresso no "Manifesto antropofágico", de Oswald de Andrade, ao parafrasear Shakespeare: “Tupi or not tupi, that is the question!” (Andrade 1928: 3).

A presença dos índios suscita indignação e revolta e remete a questões ainda sem resposta: O que é o Brasil que a Maison du Brésil espelha? O que deseja mostrar como imagem? Um país que se orgulha a tal ponto de sua pluralidade étnica e da vivência da diversidade que a elege como representação preponderante e a expõe na porta de entrada de um patrimônio histórico brasileiro na 
França? Ou a representação de um exotismo idílico e hedonista? Essas questões remetem a processos educacionais plenos, que colocam em diálogo o universo formal de pesquisadores que têm a Maison du Brésil como referência habitacional do seu séjour universitário francês, e um processo de aprendizado situacional e não escolar que altera a percepção do Brasil no exterior em diálogo e interface com o mundo francês.

A aproximação dos estudos das casas - a Maison du Brésil e a tamiriki - nos permite destacar alguns encontros, entre eles questões relacionadas à identidade e à memória social. O reforço identitário talvez seja um dos aspectos que mais podemos sublinhar nesses casos tão distintos. Assim, o que é ser brasileiro morando em Paris? Por que morar na "Maison" reforça esse aspecto identitário brasileiro? E, no caso ameríndio, o que é ser katxuyana? Por que a construção de uma casa é tão importante para os katxuyana nesse sentido? Outro aspecto que articula uma e outra pesquisa está no campo da memória social: Como essas casas acionam memórias daqueles que as habitam? O que lembram os brasileiros moradores da "Maison"? E, entre os katxuyana, que memórias foram acionadas?

Se, por um lado, a pesquisa da Maison du Brésil remeteu a essas e outras questões, como a edificação de fronteiras (Ortiz 2000) e de um território brasileiro em Paris, por outro, a multiplicidade dos sentidos do habitar e da casa (Rapoport 1972; Bromberger 2012; Philip L. Wagner cit. em Rapoport 1972: ix) a aproxima da pesquisa sobre a casa indígena tamiriki. A confluência entre antropologia, história, memória, arquitetura e educação (Ingold 2013) está presente em ambas as abordagens. Entretanto, a investigação sobre a tamiriki nos leva a uma distinta perspectiva sobre o habitar. A construção desta casa revelou seu potencial educativo em um processo "nativo" de patrimonialização.

\section{A TAMIRIKI DOS KATXUYANA: SABERES E FAZERES REVELADOS NA RECONSTRUÇÃO DE UMA CASA}

O meu primeiro contato com os katxuyana ${ }^{4}$ foi em 2009, na aldeia Santidade, no município paraense de Oriximiná, quando pude observar a construção de uma grande casa circular de telhado cônico - a tamiriki. Ainda naquele momento, os moradores mostraram o projeto "Tamiriki: construindo uma casa e reconstruindo uma cultura", escrito com a ajuda da antropóloga Denise Grupioni e selecionado pelo edital "Prêmio Culturas Indígenas", do Ministério da Cultura (MinC). ${ }^{5}$ Durante os poucos dias na aldeia, ouvi dos velhos suas

4 Sobre os katxuyana, ver Frikel (1970), Gallois e Ricardo (1983), Grupioni (201 1), Girardi (201 1). A grafia do nome do grupo mudou em 2015, passando de Kaxuyana para katxuyana.

5 Projeto da responsabilidade da Apitikatxi - Associação dos Povos Indígenas Tiriyó, Kaxuyana e Txikuyana, apresentado na edição de 2007 do Prêmio Culturas Indígenas. 
histórias sobre "a cultura katxuyana". Eram falas nostálgicas e lembranças relatadas com muita alegria, que indicavam também preocupação com o futuro.

Os moradores dessa aldeia são parentes - consanguíneos ou afins - da família extensa de João do Vale Pekiriruwa e seu de filho Mauro Makaho, respectivamente ex e atual caciques da aldeia. Honório Awahuku e Juventino Petirima Junior, importantes informantes durante a pesquisa, também são seus parentes. Honório e Juventino são filhos de um antigo líder katxuyana, Juventino Matxuwaya e tiveram grande protagonismo no processo de regresso de parte do povo katxuyana para reocupar seu território às margens do rio Cachorro, em Oriximiná.

Depois de décadas longe daquele lugar, convivendo com o povo Tiriyó, no Parque do Tumucumaque, alguns katxuyana voltaram a ocupar seu território. ${ }^{6}$ João do Vale Pekiriruwa parecia orgulhoso em me mostrar Santidade, uma antiga aldeia do povo katxuyana que havia sido recém-aberta, em 2003, e onde vivem desde então.

Ao longo da pesquisa sobre a tamiriki foram desvelados alguns significados da casa que mobilizaram os katxuyana a retomar um tipo construtivo abandonado por quase meio século, desde que deixaram seu território. A dimensão educativa da casa se revelou importante no processo de reocupação da região do rio Cachorro e no reforço identitário de ser katxuyana. Aspectos construtivos, o uso e as escolhas de materiais, o conhecimento (saber-fazer), bem como aspectos de solidariedade vicinal foram elementos que apareceram nos depoimentos de alguns moradores da aldeia - entre os velhos e velhas, entre os homens maduros e as lideranças.

A coleta de dados se deu a partir de trabalho de campo etnográfico realizado nessa aldeia entre 2010 e 2013. Durante esse trabalho, foi possível observar anciões e homens maduros preocupados em garantir que seu kwe'tohkumu, sua tradição, não desaparecesse e fosse ensinada aos jovens. A expressão kwe'tohkumu poderia ser apreendida a partir do conceito de "cultura". ${ }^{7}$ Traduzida para o português, seria "nosso jeito de ser e viver" e, por isso, o jeito de ser e viver katxuyana. Nesse exercício interpretativo, o termo "tradição" foi tomado conforme Grünewald (2012), ao afirmar que a tradição é sustentada por uma memória coletiva que, atualizada de forma prática, funciona para organizar o passado em relação ao presente; essa memória atualiza o passado.

Reconstruir uma casa como a tamiriki, confeccionar certos artefatos e realizar festas e cerimônias nessa casa se imbricam em um complexo processo que evidencia o esforço empreendido por esses katxuyana em torno das memórias de seus antepassados e de seu repasse às novas gerações. Se, por um lado, o

6 Sobre o processo migratório pelo qual passou o povo, ver Frikel (1970), Queiroz e Girardi (2012).

7 Uso o termo “cultura” (entre aspas) no sentido explicado por Cunha (2009), ou seja, aquilo que é dito acerca da cultura num exercício de reflexividade sobre ela. 
termo "patrimônio" não é empregado corriqueiramente pelos katxuyana, por outro, muitas vezes escutei o termo "resgate" na referência a esse processo. Seria possível, então, afirmar que esse "resgate" é uma versão "nativa" de patrimonialização. ${ }^{8}$

A construção da casa evidencia uma espécie de objetivação da cultura katxuyana, baseada na memória dos velhos. O aprendizado da construção da tamiriki se desvelou como aprendizado de um saber-fazer importante, a ser vivenciado e transmitido aos jovens. Essa aprendizagem se mostrou uma forma de salvaguardar esse patrimônio imaterial. O aspecto patrimonial, nesse caso, é um exercício político desse grupo para fazer perseverar a própria identidade. A tarefa de reconstruir uma tamiriki foi um exercício de fortalecimento de tradições, do "jeito de ser katxuyana".

Essa preocupação com a manutenção de sua cultura se iniciou antes mesmo da abertura da aldeia em 2003. Para tanto, os katxuyana estabeleceram alianças e aproximações em "redes de relações" (Gallois 2005) com outros povos indígenas, com organizações não governamentais (ONGs), com a Fundação Nacional do Índio (Funai), com missionários e, também, com outros parceiros como, por exemplo, antropólogos e pesquisadores.

Em 2009, quando construíram a tamiriki, os katxuyana tiveram dificuldades e, por isso, convidaram alguns outros ameríndios para ajudá-los. As dificuldades em relembrar uma prática construtiva deixada de lado havia décadas e o fato de existirem poucos homens maduros na aldeia levaram os katxuyana a pedir auxílio vicinal aos waiwai. As casas comunais em geral, e as circulares em particular, são recorrentes em aldeias próximas à Santidade, como aquelas ocupadas por outros povos karib ao longo do rio Mapuera. Também nessas aldeias, a casa grande é usada para festas, reuniões e cultos religiosos. Assim, não é a excepcionalidade da tamiriki (se não idêntica, muito similar a essas outras casas grandes) que a faz importante no processo de reocupação do território katxuyana, mas a relevância que os próprios katxuyana atribuem a ela como indicador identitário.

$\mathrm{Na}$ etnografia da tamiriki, a descrição do sistema construtivo, das características da casa e seus usos mostrou ainda o sentido a ela atribuído pelos katxuyana como locus de sociabilidade, numa alusão à sua função como casa comunal, casa de "gente reunida". Se a construção dessa casa foi financiada pelo Prêmio Culturas Indígenas, se houve uma intervenção externa na elaboração do projeto submetido ao edital do prêmio e até em sua construção com

8 Aqui, o termo patrimonialização não remete a processos intermediados pelo Estado, mas à noção de que diferentes grupos selecionam elementos de sua cultura para serem preservados e lembrados. Esse exercício político, nem sempre consciente, está profundamente articulado ao conceito de tradição nos termos de Cavalcanti e Fonseca: "toma-se a tradição no seu sentido etimológico de dizer através do tempo, significando práticas produtivas, rituais e simbólicas que são constantemente reiteradas, transformadas e atualizadas" (2008: 12). 
os vizinhos waiwai, parece clara a correlação entre a tamiriki como expressão desse processo de valorização da cultura e o que vem sendo efetivado pelos katxuyana para reforçar seu kwe'tohkumu e fortalecer a figura da liderança, o pata yotono. 9

A necessidade e a importância de espaços de sociabilidade entre povos indígenas são descritas em obras como Habitações Indígenas, organizada por Novaes (1983). De sua reflexão nos interessa a explicação sobre os espaços de sociabilidade das casas comunais entre indígenas. ${ }^{10}$ Como afirma a autora, as casas comunitárias - espaço público por excelência - são ponto de referência a ser tomado para a elaboração da identidade. Esses espaços são muitas vezes distintos ou complementares daqueles chamados íntimos ou privados.

Durante a pesquisa, registrei cinco tipos construtivos, conforme a planta baixa. Uma delas é a casa grande (kwama akani), uma casa comunal, também denominada pata yotono kwama (casa do dono da aldeia). A casa comunal, habitação por excelência dos katxuyana antes de deixarem seu território no rio Cachorro, era a unidade habitacional mais importante da aldeia, onde viviam o cacique e sua família extensa. Em muitos relatos, essa casa tinha o formato da tamiriki, uma casa de planta baixa circular e cobertura cônica, instalada diretamente no solo. Esse tipo construtivo era o que existia na antiga aldeia Santidade, onde o líder Juventino Matxuwaya viveu com sua família. Embora fosse moradia de longa duração, não era uma casa permanente.

Hoje, a tamiriki ainda mantém o mesmo tipo construtivo e planta baixa. Continua sendo um espaço comum de sociabilidade e é usada nas festividades, reuniões e para receber visitantes. Contudo, o cacique e sua família extensa não moram mais nessa casa. Até 2012, uma igreja e a escola formal funcionavam nesse espaço. Em 2015, quando fui visitá-los, essa tamiriki tinha caído em desuso, pois seu telhado de palha havia se deteriorado.

Por outro lado, não satisfeitos com o resultado da tamiriki erguida entre 2009 e 2010, que ficou oktxemenho (nem boa nem ruim), pois é uma casa "modelo waiwai", no ano de 2013, os katxuyana decidiram construir outra. A nova tamiriki, com dimensões menores que a anterior, tem formato "tradicional"; eles dizem que é "modelo katxuyana" (figura 3). ${ }^{11}$ Reforçando novamente a dimensão educativa da construção da casa, o procedimento de edificação dessa vez envolveu vários jovens. Todo esse processo foi intermediado pelo

9 Pata yotono é literalmente, o dono da aldeia, dono do lugar, cacique: o homem responsável pela abertura de uma nova aldeia, a quem compete, segundo o sistema de organização social dos povos karib da Guiana, coordenar o trabalho coletivo, receber visitantes, enfim, liderar o grupo. Sobre a figura de liderança, ver Frikel (1970), Rivière (2001) e Girardi (2011).

10 O conceito de sociabilidade remete à ideia de criação de um espaço de boa convivência entre pessoas. Esse é um aspecto importante para os povos da Guiana e de outros lugares na Amazônia. Sobre isso, ver Overing e Passes (2000). Entretanto, existem usos diferenciados para este termo.

I I Sobre detalhes do processo construtivo de uma e outra tamiriki, ver Russi (2014). 


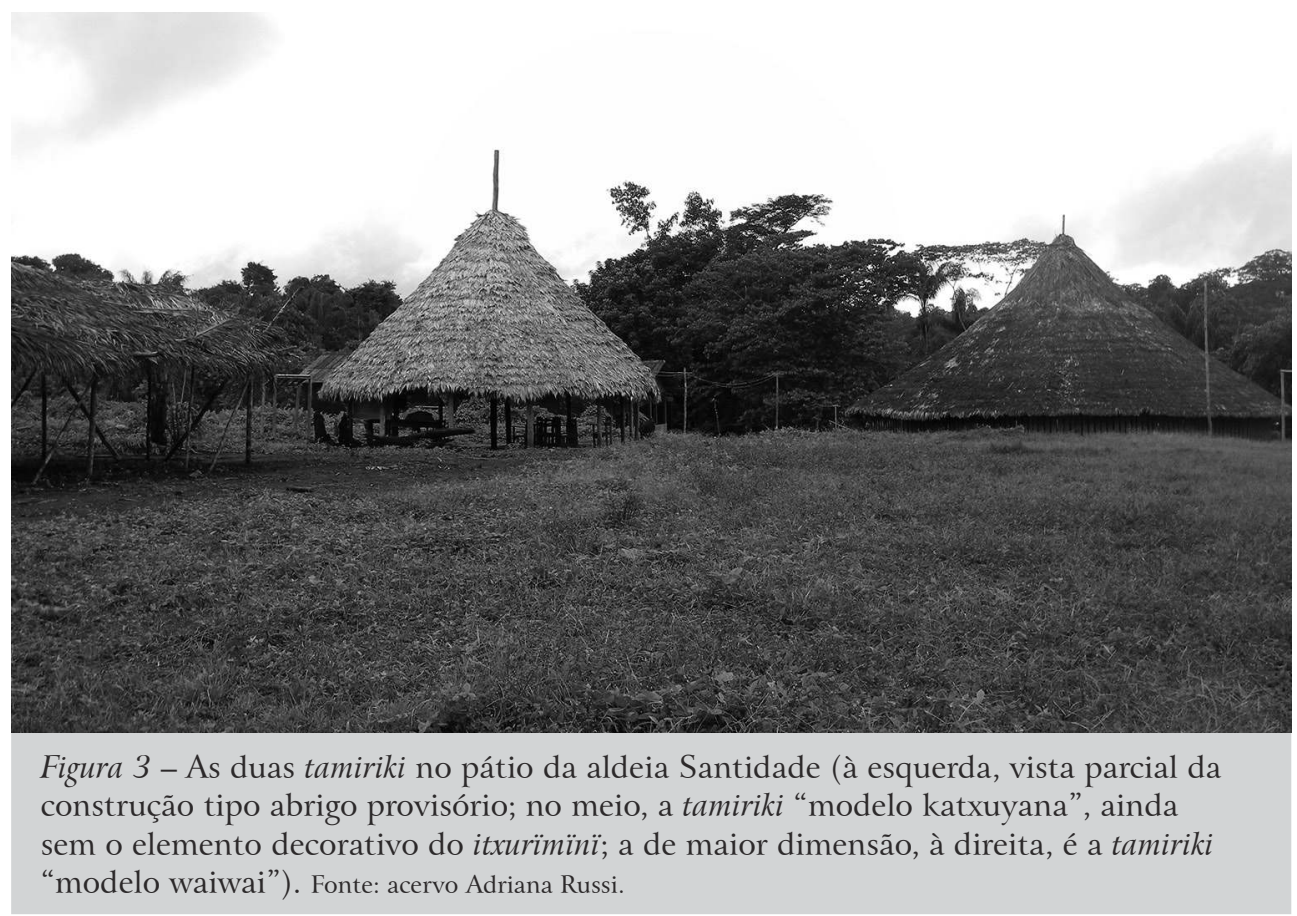

cacique que ouvia os anciãos e repassava o ensinamento aos jovens. Em todos os momentos de sua construção, as memórias dos velhos eram acionadas. Em vários depoimentos sobre isso, os velhos e as lideranças falavam do resgate da cultura, ou seja, de sua dimensão patrimonial.

Para construírem a tamiriki "modelo katxuyana", os velhos acompanharam de perto e orientaram o cacique sobre cada uma das etapas da nova casa. Naquele momento, o "modelo de memória" (Portocarrero 2010) vinha à tona e ocupava suas narrativas. Eles conversavam entre si, trocavam ideias e explicavam aos homens maduros o que fazer. Estes, por sua vez, ensinaram os jovens aprendizes e, juntos, levantaram a nova casa. Cabia ao cacique organizar cada etapa.

O processo educativo de saber-fazer não se restringiu apenas à construção da casa, mas envolveu diferentes momentos de trocas intergeracionais para ensinar artesanato, danças e rituais. Mauro Makaho, cacique e professor da educação formal, evidenciou a preocupação da geração mais velha em garantir a transmissão dos saberes:

"Boa tarde, meu nome é Mauro, estamos aqui trabalhando com os jovens de $7 .^{\circ}$ e $8 .^{\circ}$ ano, estamos trabalhando o artesanato aqui, ensinando os jovens pra saberem fazer o seu artesanato. A única coisa que a gente pode ensinar aos nossos filhos: saber fazer tipiti, abano, peneira. [...] tudo que é 
da alimentação, a gente faz por meio do artesanato. Então, nossos alunos merecem aprender com a gente aqui dentro da nossa casa grande, tamiriki. A gente chama na língua katxuyana tamiriki, casa grande, onde nós ensinamos nossos filhos. [...] É isso que a gente está fazendo aqui na nossa escola, porque a gente estuda um pouco diferente. Nosso estudo assim, mais na nossa língua, é conhecer a cultura [...]. É muito difícil pra nós também, pois só os velhos sabem fazer esse tipo de trabalho. Agora nós professores estamos aprendendo também, e aí, estamos ensinando o que nós aprendemos com os nossos pais" [trecho do depoimento de Mauro Makaho, junho de 2013].

A reconstrução da tamiriki possibilitou compreender o valor simbólico que os katxuyana atribuem a essa casa. Se em 2003, quando reabriram a aldeia, o grupo se limitava a duas ou três famílias, com o crescimento do grupo surgiu a necessidade de um espaço público que abrigasse a coletividade. Essa casa comunal poderia ter diferentes tipos de planta baixa. Entretanto, eles escolheram o tipo da tamiriki como espaço de sociabilidade a ser construído, remetendo ao formato da casa comunal que existia na aldeia antes da migração.

Embora as casas circulares fossem comuns na região da Guiana, usadas sobretudo como habitação, já nos anos de 1970, Frikel (1970, 1973) observou que, passadas três décadas desde os primeiros contatos que teve com os katxuyana, no princípio dos anos de 1940, o sistema construtivo e a organização espacial de suas aldeias haviam sofrido modificações. Gallois e Grupioni (2003) também afirmam que isso teria ocorrido com outros povos karib da região.

Na tamiriki erguida em 2009 faltavam alguns elementos decorativos, como o itxurïmïnï. Analisando a figura 4, esse elemento decorativo, ausente na tamiriki "modelo waiwai", tem quase a mesma dimensão da casa, ou seja, não é apenas um pequeno detalhe. Essa iconografia fora de escala revela o quão importante é esse elemento. Nesse caso, o enfeite não é um mero pormenor construtivo. Por isso, eles se mobilizaram em 2013 para fazer uma nova tamiriki, concluída no ano seguinte e de tamanho reduzido. Essa pequena casa foi construída de forma apropriada, materializando melhor o valor simbólico atribuído à tamiriki. Ao destacarem esse elemento decorativo, os katxuyana reiteram sua estratégia de defesa patrimonial. Essa casa se mostra reveladora da identidade katxuyana e seu processo construtivo enfatiza uma tradição, trazendo à tona tanto sua dimensão educativa quanto sua dimensão patrimonial.

Ao regressarem para seu território, os katxuyana procuraram também reforçar a figura política do cacique, o chefe, o dono da aldeia, enfraquecida enquanto viveram com outros ameríndios. Neste caso, a reconstrução da tamiriki assumiu um valor simbólico importante, ao se revelar também como estratégia para enfatizar a figura da chefia. Se hoje a tamiriki não é mais a moradia 


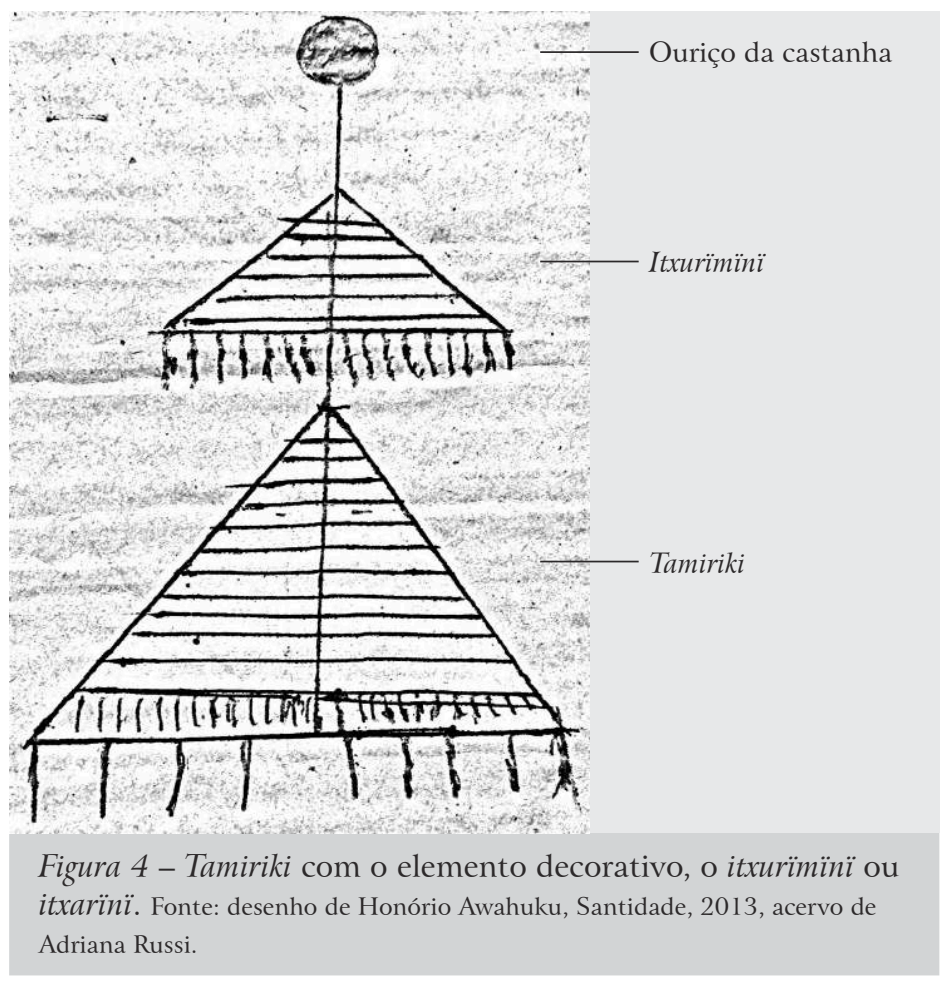

do cacique, os katxuyana explicam que tamiriki é a pata yotono kwama (casa do dono da aldeia, casa do chefe). Assim, a escolha da tamiriki é emblemática, pois esta era a habitação do cacique com sua família extensa antes da migração. Como relatado, se fosse apenas pela necessidade de um espaço de sociabilidade, os katxuyana poderiam ter construído outros tipos de casa comunal. Entretanto, optaram por construir uma casa comunal no formato da tamiriki, um tipo construtivo que fazia anos que não construíam. Além da lembrança dos antepassados, a escolha se voltou para o modelo da antiga casa ocupada pelo líder Juventino Matxuwaya e sua família extensa.

É na tamiriki que eles fazem suas brincadeiras durante as festas, como procurar balas ou frutas escondidas, contam piadas, especialmente com o cacique, dançam e protagonizam algumas performances como, por exemplo, a exibição do resultado de caçadas coletivas. Na tamiriki, os katxuyana, hoje evangélicos, celebram as festas de Páscoa e Natal. Durante o Natal, cujas comemorações se desdobram por algumas semanas e vão até o início do ano, algumas regras sociais ficam suspensas e certos comportamentos, antes proibidos ou censurados, são interpretados como divertidas brincadeiras. Nessa casa, quase semanalmente, a comunidade da aldeia se reúne para tomar suas decisões ou para discutir assuntos de interesse coletivo (Russi 2014). 


\section{AS DUAS CASAS: SINGULARIDADES E RECORRÊNCIAS}

A análise sobre a tamiriki remete, ainda, ao pensamento de Rapoport (1972) sobre a necessidade que os grupos humanos têm de um lugar de sociabilidade, que pode ser construído ou não, temporário ou permanente. Diferente dos espaços privados (íntimos), os espaços de sociabilidade se caracterizam por uma ocupação coletiva. Esses espaços de sociabilidade estão presentes nas etnografias sobre a Maison du Brésil e sobre a tamiriki.

Inúmeros autores escreveram sobre a casa e/ou sobre a forma como as sociedades materializam sua ocupação em dado território, resultando em distintos formatos das edificações. Como aponta Rapoport (1972), tamanha variedade não se explicaria se analisássemos apenas as forças secundárias - há poucos tipos distintos de clima, um número limitado de materiais e de outros aspectos físicos. Essa diversidade construtiva decorre de múltiplas formas de materialização do "ambiente desejado", expressando concepções de mundo e tipos de vida diferentes. Para esse autor, as formas de construção resultam mais das intenções e desejos do grupo que de desejos individuais. É por isso, ele afirma, que a construção tem um "valor simbólico", pois símbolos "permitem a uma cultura concretizar suas ideias e seus sentimentos" (Rapoport 1972: 66). Nas etnografias aqui apresentadas, esse "valor simbólico" se evidencia de distintas maneiras nas duas casas.

A ideia de espaço público e as diferentes formas do sentido do habitar, em suas dimensões educativas e patrimoniais, também se revelaram nas pesquisas aqui relatadas. Na etnografia da Maison du Brésil, os processos educativos não formais são compartilhados entre os moradores temporários dessa habitação e se relacionam a diferentes processos de desterritorialização de identidades em um território brasileiro em Paris.

A análise das duas casas nos permite retomar o que Ruegg (2011:26) afirma sobre a representação e o imaginário que elas inspiram. Conforme os dados de ambas as pesquisas, foi possível reconstruir a sociologia, a história das ideias e a cosmologia das diversas concepções de habitar. Nesse sentido, o que aproxima as experiências das casas estudadas é sua dimensão educativa e patrimonial. Por um lado, essas casas se configuram como habitação, em seus aspectos arquitetônicos, mostrando-se ora como espaço público, ora como espaço privado; por outro lado, revelam dimensões que permitem pensar a casa como espaço de processos de patrimonialização, logo, objeto de práticas educativas.

As duas etnografias ilustram a noção de Ortiz (2000) da casa como território simbólico e de desejos definidores de identidades. Comparando essas experiências, poderíamos destacar como recorrências as indicadas no quadro 1 .

Certamente, uma das mais evidentes singularidades nessa comparação são as distintas arquiteturas em suas dimensões e seus aspectos formais, técnicas construtivas e uso de materiais. Se, por um lado, os katxuyana participaram 
Quadro 1

Recorrências nas casas analisadas

Recorrências

Lugar de reforço identitário

Lugar de memórias

Espaço de sociabilidade
Maison du Brésil

Ser brasileiro longe do país

Lembranças do país distante

\section{tamiriki katxuyana}

Ser katxuyana na reapropriação de seu território

Lembranças dos antepassados

Lugar de festividades e de receber visitantes

da construção da casa que usam, o mesmo não ocorreu no caso dos brasileiros, que apenas usam a Maison du Brésil numa passagem temporária. Por outro lado, ambas as casas deixam marcas nas histórias de seus habitantes.

Por fim, a partir dos relatos coletados entre os habitantes das duas casas, observamos o quanto os aspectos simbólicos e educativos a elas associados foram realçados. Esses relatos sobre o habitar esses espaços revelaram suas particularidades, materializadas a partir da diversidade de usos e sentidos que cada um desses grupos atribui a essas casas.

\section{BIBLIOGRAFIA}

ANDRADE, Oswald de, 1928, "Manifesto antropofágico", Revista de Antropofagia, 1: 3, 7. BOURDIEU, Pierre, 1980, Les sens pratique. Paris, Les Editions de Minuit.

BRANDÃO, C. Rodrigues, 2002, A Educação como Cultura. Campinas, Mercado das Letras. BROMBerger, Christian, 2012, "Habitation", em Pierre Bonte e Michel Izard (dirs.), Dictionnaire de l'ethnologie et de l'anthropologie. Paris, Quadrige/PUF, 317-320.

BRUM, Ceres Karam, 2014, Maison du Brésil: Um Território Brasileiro em Paris. Porto Alegre, Evangraf.

CAVALCANTI, Maria Laura, e Maria Cecilia Londres FONSECA, 2008, Patrimônio Imaterial no Brasil: Legislação e Políticas Estaduais, Brasília, UNESCO/Educarte.

COSTA, Maria Heloisa Fénelon, e Hamilton Botelho MALHANO, 1987, "Habitação indígena brasileira”, em Darcy Ribeiro (org.), Suma Etnológica Brasileira. Petrópolis, Vozes, 27-92.

CUNHA, Manuela Carneiro da, 2009, Cultura com Aspas e Outros Ensaios. São Paulo, Cosac Naify.

FARIA, Luís de Castro, 1951, "Origens culturais da habitação popular do Brasil”, Boletim do Museu Nacional: Antropologia, 12: 1-72.

FRIKEL, Protásio, 1970, Os Kaxuyana: Notas Etno-Históricas. Belém, Museu Paraense Emilio Goeldi. 
FRIKEL, Protásio, 1973, Os Tiriyó: Seu Sistema Adaptativo. Hanôver, Kommissionsverlag Münstermann-Druck.

GAllOIS, Dominique (org.), 2005, Redes de Relações nas Guianas. São Paulo, Humanitas/ FAPESP.

GAlloIS, Dominique, e Carlos A. RICARDO (orgs.), 1983, Povos Indígenas do Brasil: Amapá e Norte do Pará. São Paulo, CEDI.

GALloIS, Dominique, e Denise Fajardo GRUPIONI, 2003, Povos Indígenas no Amapá e Norte do Pará: Quem São, Onde Estão, Quantos São, Como Vivem e o Que Pensam. São Paulo, IEPÉ. GIRARDI, Luisa, 201 1, Gente do Kaxuru: Mistura e Transformação entre Um Povo Indígena KaribGuianense. Belo Horizonte, Universidade Federal de Minas Gerais, dissertação.

GRIAUlE, Marcel, 1966, Dieu d'eau: entretiens avec Ogotemmêli, 1948, Paris, Librarie Arthème Fayard.

GRÜNEWALD, Rodrigo de Azeredo, 2012, “Tradição”, em Antonio Carlos de Souza Lima (org.), Antropologia e Direito: Temas Antropológicos para Estudos Jurídicos. Rio de Janeiro/ Brasília, Contra Capa/LACED/ABA, 186-197.

GRUPIONI, Denise Fajardo, 201 1, "Dispersão e sedentarismo nas TIs Tumucumaque e Paru d'Este”, em Beto Ricardo e Fany Ricardo (orgs.), Povos Indígenas do Brasil (2006-2010). São Paulo, Instituto Socioambiental, 321-323.

HANNERZ, Ulf, 1990, "Locais e cosmopolitas", em Mike Featherstone (org.), Cultura Global. Petrópolis, Vozes, 251-266.

INGOLD, Tim, 2010, "Da transmissão de representações à educação da atenção", Educação, 33 (1): 6-25

INGOLD, Tim, 2013, Making: Anthropology, Archaelogy, Art and Archictecture, Londres, Routledge.

LAVE, Jean, 1996, "Teaching as learning in practice", Mind, Culture and Activity, 3 (3): 149$-165$.

LÉVI-STRAUSS, Claude, 1957, Tristes Trópicos. São Paulo, Editora Anhembi.

LÖFGREN, Orvar, 1999, "Crossingborders: the nationalization of anxiety", Ethnologia Scandinavica, 29: 5-27.

MAUSS, Marcel, 2003, Sociologia e Antropologia. São Paulo, Cosac Naify.

NOVAES, Sylvia Caiuby (org.), 1983, Habitações Indígenas. São Paulo, Nobel/EdUSP.

ORTIZ, Renato, 2000, O Próximo e o Distante: Japão e Modernidade-Mundo. São Paulo, Brazilians.

OVERING, Joanna, e Allan PASSES, 2000, The Anthropology of Love and Anger: The Aesthetics of Conviviality in Native Amazonia. Londres/Nova Iorque, Routledge.

PORTOCARrero, José Afonso Botura, 2010, Tecnologia Indígena em Mato Grosso: Habitação. Cuiabá, Entrelinhas.

QUEIROZ, Ruben Caixeta de, e Luisa Gonçalves GIRARDI, 2012, “Dispersão e concentração indígena nas fronteiras das Guianas: análise do caso Kaxuyana”, Revista Brasileira do Caribe, 13 (25): 15-42.

RAPOPORT, Amos, 1972, Pour une anthropologie de la maison. Paris/Bruxelas/Montréal, Dunod. RIVIÈRE, Peter, 1996, "Houses, places and people: community and continuity in Guiana", em Janet Carsten e Stephen Hugh-Jones (orgs.), About the House: Lévi-Strauss and Beyond. Cambridge, Cambridge University Press, 189-205.

RIVIÈRE, Peter, 2001, O Indivíduo e a Sociedade na Guiana: Um Estudo Comparativo sobre a Organização Social Ameríndia. São Paulo, Editora USP. 
ROSAles, Marta Vilar, 2015, As Coisas da Casa: Cultura Material, Migrações e Memórias Familiares. Lisboa, Imprensa de Ciências Sociais.

RUEGG, François, 201 1, La maison paysanne: histoire d'un mythe. Paris, Infolio.

RUSSI, Adriana, 2014, Tamiriki, Pata Yotono Kwama: A Reconstrução de Uma Casa, a Valorização de Uma Cultura e o Protagonismo dos Ameríndios Kaxuyana às Margens do rio Cachorro (Oriximiná/PA). Rio de Janeiro, Universidade Federal do Estado do Rio de Janeiro, tese. SALIM, Inês Machado, 2013, "Maison du Brésil: cronologia de fatos", documento inédito digitalizado.

Receção da versão original / Original version

$2017 / 02 / 08$

Receção da versão revista / Revised version

$2017 / 08 / 21$

Aceitação / Accepted

$2018 / 04 / 10$ 